\title{
Relatividade Ontológica e Subdeterminação; Naturalismo e Pirronismo
}

\author{
Marcos Bulcão Nascimento \\ UFBA \\ marcosbulcao@yahoo.com.br
}

resumo A tese quine a na da relativida de ontológica é certamente um dos aspectos mais conhecidos de sua obra. 0 que freqüentemente passa sem notícia, entretanto, é que sua concepção de subdeterminação mudou ao longo de sua obra e que isso altera substancialme nte algumas conseqüências-chave normalme nte tira das da tese supra-citada. Caberá aqui examinar, portanto, tais mudanças conceituais e explorar algumas de suas cons eqüências, particularmente aquelas relacionadas ao realismo. Caberá, ainda, tentar aproximar a postura realista quineana com o que se poderiapensar como uma postura realista neopirrônica.

palavras-chave naturalismo; relatividade ontológica; subdeterminação; realismą linguagem; neopirronismo

Durante toda sua vida Quine declarou ser um realista. Durante toda sua vida, não menos, se instaurou a polêmica quanto a ele poder ser, de direito e de fato, um realista. A razão principal, ou uma delas em todo caso, alega-se, é que sua tese da relatividade ontológica seria incompatível com uma postura realista em ciência.

O que argumentaremos aqui é que essa alegada incompatibilidade é fruto de uma incompreensão, de um lado, do que está em jogo no naturalismo quineano e, de outro, do que está em jogo na própria tese da relatividade ontológica, particularmente em sua relação com a importante tese de subdeterminação.

Recebido em 08 de abril de 2007. Aceito em 19 de setembro de 2007.

doispontos, Curitiba, São Carlos, vol. 4, n. 2, p.133-158, outubro, 2007 


\section{4}

Pelo primeiro aspecto, esclarece-se que o realismo quineano não se concebe do mesmo modo que o realismo científico, permitindo ao primeiro - mas não ao segundo - conciliar-se com a tese da relatividade ontológica.

Pelo segundo, tenta explorar-se, ainda que talvez um tanto brevemente, um aspecto da filosofia quineana que talvez venha sendo negligenciado, a saber, que a visão de Quine a respeito de subdeterminação ganhou diferentes contornos ao longo de sua obra e que isso pode ter conseqüências importantes para o modo como enxergamos tanto a tese da relatividade ontológica quanto o realismo quineano.

Feito esse trabalho preliminar, gostaríamos ainda de explorar (ou, em todo caso, indicar) uma possível - ainda que muitos a reputem improvável ou mesmo impossível - afinidade filosófica entre o realismo naturalista quineano e o que se poderia conceber como uma postura realista neopirrônica.

O realismo científico, nós podemos definir brevemente como uma tese filosófica que argumenta a favor da idéia de que as teorias científicas descrevem o mundo apropriadamente. Admite que a ciência ambiciona a verdade e que tem tido sucesso em sua busca. Seu argumento principal, bastante plausível à primeira vista, é que ou as teorias científicas da ciência moderna realmente descrevem apropriadamente o mundo (ainda que apenas aproximadamente), ou o seu incrível sucesso preditivo só poderia ser obra de um milagre (BOYD, 1984, p. 49).

$\mathrm{O}$ realismo científico entende, então, que as teorias científicas oferecem sentenças (aproximadamente) verdadeiras, cujos termos centrais típica e relevantemente se refe rem a objetos no mundo. Isto significa dizer que a ciência nos propicia adquirir não apenas conhecimento empírico, tecnológico (conhecimento dos observáveis, manifesto no acerto das predições científicas, seu sucesso instrumental), como também conhecimento teórico (afirmação da existência das entidades pressupostas por suas leis, mesmo daquelas que são inobserváveis).

De fato, é uma característica marcante das teorias científicas atuais a postulação ou assunção de existência de determinadas entidades ou estru- 
turas inobserváveis subjacentes aos fenômenos macroscópicos que observamos. Assim, por exemplo, teorias fisicas dizem que as mesas que observamos são na verdade compostas de moléculas, as quais são compostas de átomos, os quais são compostos de outras partículas ainda menores, como elétrons e quarks.

A partir desse procedimento padrão no modo de fazer ciência hoje, o argumento central do realismo científico diz então que devemos, dado o fantástico sucesso preditivo, crer que essas entidades inobserváveis supostas ou postuladas (a) realmente existem e (b) são aproximadamente tais como as descrevem as teorias científicas maduras. A essas duas, acrescenta-se ainda uma terceira tese, a saber, que (c) a substituição eventual de uma teoria madura por outra implica uma preservação relevante da estrutura explicativa da teoria anterior (isto é, há uma depuração, não propriamente uma substituição, no quadro conceitual em questão).

Com efeito,

"o realista [científico] deve poder defender uma tese histórica a

respeito da história recente das ciências relevantes segundo a qual suas realizações envolvem aproximado conhecimento teórico e de acordo com a qual progresso teórico tem sido feito...". "O realista deve empregar uma concepção de verdade aproximada, de conhecimento aproximado e de progresso teórico que dê sentido ao recente desenvolvimento das teorias científicas" (BOYD, 1990, pp. 355-6).

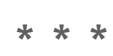

Contudo, a tese realista científica enfrenta algumas dificuldades. Argumentos contra as noções de verdade aproximada, de progresso e preservação relevante (dos elementos de uma teoria na outra), além da tese da indistingüibilidade evidencial e dos importantes casos advindos da história da ciência em que entidades postuladas por teorias muito bem sucedidas foram mais tarde descartadas (o caso do éter sendo o mais famoso deles) podem ser aqui mencionados.

Um dentre esses nos interessa particularmente, a saber, a tese da indistinguibilidade evidencial, mais conhecido como problema da subdeterminação da teoria pelos dados. Realmente, se diferentes teorias podem 


\section{6}

ser suportadas pelo mesmo conjunto de dados, como assumir uma como sendo a verdadeira, em detrimento da outra?

Nesse ensejo, a tese da relatividade ontológica parece desferir à tese realista científica golpe ainda mais duro. De fato, Quine mostra que a relação entre a teoria e seu suporte empírico depende antes da estrutura lógica da teoria do que de sua ontologia assumida. Com efeito, ele mostrou que se pode alterar a ontologia de uma teoria qualquer sem comprometer seu sucesso preditivo, isto é, sem alterar sua relação de suporte evidencial.

Mas se isso é correto, então não se veria como deduzir - do fato de uma teoria científica ser extremamente bem sucedida - que sua ontologia é a verdadeira ontologia do mundo, no sentido de ser a única e correta ontologia capaz de dar conta dos fenômenos observados e observáveis. O que ele claramente mostra é que "é indiferente para o sucesso da teoria em suas predições" possuir esta ou aquela ontologia: para propósitos estritos de predição e suporte evidencial, o que importa é a estrutura lógica da teoria, as conexões lógicas entre suas sentenças (QUINE, 1990, p. 31).

Ora, neste caso, o argumento central do realismo científico - a respeito da passagem do sucesso preditivo para a existência dos objetos postulados parece estar severa ou mesmo irremediavelmente comprometido.

***

Entretanto, tudo isso posto, e mesmo depois de avançar um argumento que acaba por fazer "referência e ontologia retrocederem assim ao status de meros auxiliares" (QUINE, 1990, p. 31), Quine não assume uma posição anti-realista. Ao contrário, Quine diz de si mesmo que ele é antes um "realista robusto e irregenerado". O que é ainda mais interessante é que Quine declara - aparentemente bem ao gosto da tese realista científica - que "o mundo é como a ciência natural diz que ele é, na medida em que a ciência está certa; e nosso julgamento quanto a se ela está certa, sempre tentativo, responde perante o teste experimental das predições" (QUINE, 1992, p.9, nossos grifos). Pareceria, então, que Quine estaria, de algum modo, como que reeditando o argumento realista científico da passagem do sucesso preditivo à assunção ontológica. Ora, certamente 
não é esse o caso. Mas, não o sendo, onde, então, situar a diferença entre essa afirmação quineana e aquela do realismo científico? Em uma palavra, no naturalismo.

Cabe investigar, portanto, que arcabouço conceitual o naturalismo disponibiliza que permite neutralizar os impactos aparentemente negativos - tanto da falibilidade alegada da ciência, quanto da tese da relatividade ontológica - no realismo quineano, embora não no realismo científico.

\section{III}

Podemos desde logo perceber que, embora o problema central do realismo científico diga respeito, naturalmente, à assunção de objetos em geral, há claramente um enfoque especial concernindo à assunção de objetos inobserváveis.

Com efeito, é em relação a estes que as principais argumentações - e objeções - têm lugar. Devemos ou não crer em objetos inobserváveis? - eis a pergunta que guia todo o debate. Com efeito, os argumentos dados - pró ou contra - dizem respeito, em sua maioria, a por que devemos estar confiantes em crer na existência de tais objetos postulados pelas nossas melhores teorias científicas ou a por que não devemos crer ou, pelo menos, por que devemos permanecer agnósticos a respeito de tal existência. A confiança na crença de tais objetos, vimos brevemente, está atrelada à confiança no sucesso das respectivas teorias científicas que os postulam. A desconfiança ou prudência, se se quiser, diz respeito à constatada falibilidade das teorias científicas, à alteração freqüente em sua ontologia (muitas vezes radical) e, conseqüentemente, à falta de uma garantia contumaz, imperiosa, definitiva, absoluta quanto a tal existência. Não havendo tal garantia, por que deveríamos dar nosso assentimento a tais objetos? Van Fraassen pode ser aqui invocado para sumariar o ponto: deveríamos crer no que as teorias científicas nos dizem a respeito dos observáveis; quanto aos inobserváveis, continuemos agnósticos (VAN FRAASSEN, 1980).

Nos objetos observáveis, assim, p a receríamos ter amplas razões para crer, teríamos razões para estarmos confiantes em sua existência. Nós poderíamos até melhorar nossas concepções quanto às suas características 
ou propriedades, mas não pareceríamos poder estar errados quanto à sua existência. A observação dos mesmos pareceria fornecer toda a garantia necessária para nossa assunção deles e nossa crença neles. Os objetos inobserváveis, ao contrário, escapariam, por definição, à possibilidade mesma de nos fornecer tal garantia. Não podendo ser observados, só podem ser assumidos a partir de uma cadeia inferencial.

O problema aqui é que, dado o desenvolvimento constante da ciência, tal cadeia inferencial pode acabar sendo posta de lado, seja porque ela se revelou equivocada, incompleta ou desnecessária, seja porque uma outra teoria, melhor, veio a oferecer um outro complexo de cadeias inferenciais que nos conduzem a uma outra ontologia inteiramente diferente. Podemos lembrar o caso do éter, que deixou, após Einstein, de ser uma entidade do mundo descrito pela ciência. Para não mencionar o clássico argumento da subdeterminação ou da própria relatividade ontológica, que nos mostram a possibilidade de diferentes ontologias com o mesmo suporte empírico e, portanto, indicam uma certa "arbitrariedade" quanto a que ontologia assumir.

Em outras palavras, seja pela falibilidade, seja pela suposta arbitrariedade envolvida nos casos de subdeterminação, não pareceríamos ter razões, garantias suficientes para crer em tais entidades. Naturalmente, dada sua utilidade no processo científico, teríamos de aceitá-las, em alguma medida, como parte da teoria; mas nossa crença, pareceria mais prudente recusá-la.

\section{IV}

Ora, acontece que o naturalismo nos oferece um novo modo de pensar as relações entre conhecimento e crença, particularmente no que diz respeito à questão da assunção ontológica. O que Quine nos faz perc eber é que nossa aceitação de uma ontologia se torna "similar em princípio à nossa aceitação de uma teoria científica, por exemplo, um sistema de física: nós adotamos, pelo menos na medida em que somos razoáveis, o esquema conceitual mais simples nos quais os fragmentos desord e nados da experiência bruta podem ser agrupados e arranjados" (QUINE, 1953, p. 6). 
Ora, acontece ainda que, dada a concepção holista de ciência, a evidência que suporta a nossa melhor teoria disponível a suporta como um todo e, nesse caso, não pareceríamos mais bem garantidos em crer numa parte da teoria (por exemplo, aquela concernente aos objetos observáveis) do que na outra. Além disso, todos os objetos são, na visão quineana, teóricos, de modo que a diferença entre os objetos observáveis e inobserváveis, se há alguma importante, é de grau.

Bem, de grau ou não, é certo que a diferença existe, e o próprio Quine concede certo "privilégio" aos objetos observáveis, lhes concede, em algum sentido, uma "maior confiabilidade". Com efeito, Quine diz acreditar inabalavelmente em coisas externas - pessoas, paus, pedras. E diz acreditar também, "se menos firmemente, em átomos e elétrons e classes" (QUINE, 1994, p. 21).

Como interpretar agora esse grau diferenciado de crença, em relação aos objetos observáveis versus objetos inobserváveis e/ou abstratos? Se as considerações que fazemos a respeito da ciência são holísticas e se, ao afirmarmos (a verdade de) uma teoria, afirmamo-la como um todo, como agora declarar maior ou menor confiança em relação às suas partes?

A ve rdade é que, sob uma reflexão cuidadosa, não há grandes mistérios aqui. Com efeito, nas próprias considerações sobre o holismo podemos perceber que, quando realizamos o teste de uma teoria, o cientista em geral já tomou sua decisão quanto a que enunciados considerar como sendo mais "vulneráveis".

Vemos, deste modo, que não é estranha ao cientista a idéia de que, embora ele possa adotar uma teoria como um todo (enquanto, por exemplo, ela se mantiver consistente com os fenômenos observados), partes de seu sistema sejam vistas como mais vulneráveis. Vulneráveis, isto é, a elas ele renunciaria mais facilmente. Tomemos as verdades matemáticas, por exemplo. Numa concepção holista, elas obteriam seu estatuto de "verdades necessárias" não porque são "analíticas" ou ve rdadeiras necessariamente por convenção lingüística, mas antes porque, ou no momento em que, o cientista entende que sua rejeição reverberaria intolerave $1-$ mente ao longo de seu sistema e, por isso, prefere re nunciar a outros grupos de enunciados a sacrificá-las.

Nesse raciocínio, o grau "superior" de confiabilidade de que os objetos observáveis parecem desfrutar poderá ser explicado pelo fato 


\section{0}

de que os enunciados que afirmam sua existência são enunciados aos quais nós também não veríamos como renunciar. Afinal, são presumivelmente os nossos conceitos mais antigos, as categorias mais enraizadas em nosso processo de conceitualização, são os conceitos sem os quais o próprio processo de sistematizar a experiência parece perder o sentido. Nesse caso, tal superioridade, a alta confiabilidade em relação aos objetos observáveis, se deveria ao fato de que não saberíamos (ou não imaginaríamos como seria) viver, sistematizar a nossa experiência, cotidiana e outra, sem fazer a eles referência (além disso, poderíamos lembrar ainda que é a tais conceitos que voltamos quando a comu nicação enfrenta problemas; é sobre eles que temos menos mal-entendidos na comunicação).

De outro lado, a "inferioridade" - e, portanto, desconfiança - em relação aos objetos inobserváveis, conversamente, estaria calcada em que, num certo sentido, podemos conceber como seria a vida, a sistematização da experiência, cotidiana e outra, sem a eles fazer referência. Concebemos isso pelo fato de que vemos a história da ciência presentear-nos com exemplos de entidades descartadas, vemos a história da ciência acenar-nos com modos revolucionários de pensar as partículas elementare s, porque vemos até mesmo a ciência acenar-nos com a possibilidade de sequer pensarmos em termos de partículas elementares.

Entretanto, se é verdade que podemos conceder algum tipo de privilégio epistemológico aos objetos observáveis, isso não deve servir de argumento, por sua vez, para a retirada da crença nos objetos inobserváveis. Isso porque, se compreendermos que tipo de evidência temos para a assunção de objetos, observáveis e inobserváveis, p o d e remos compre ender que essa "prudência agnóstica" deve dar lugar a uma crença, a uma crença matizada, por certo, mas a uma crença.

Realmente, o que devemos perceber é que a evidência que dizemos ter para a existência dos corpos de senso comum é, num certo sentido, do mesmo tipo que aquela que se pode dizer que temos para a existência de moléculas. "A postulação dos dois tipos de corpos é boa ciência na medida em que nos ajuda a formular nossas leis - leis cuja última evidência reside nos dados dos sentidos do passado, e cuja última vindicação reside na antecipação dos dados dos sentidos do futuro" (QUINE, 1966, p. 237). O ponto-chave aqui é que, 
"tendo notado, assim, que o homem não tem evidência para a existência de corpos além do fato de que sua assunção o ajuda a organizar a experiência, nós deveríamos, em vez de desacreditar a evidência para a existência de corpos, concluir: tal, então, no fundo, é o que evidência é, tanto para corpos ordinários como para moléculas” (QUINE, 1966, p. 238, nossos grifos).

O que o naturalismo faz, assim, é compreender a ciência como um empreendimento humano, falível por certo, mas que, por não haver uma filosofia primeira ou tri bunal superior, deve ele resolver seus próprios problemas, suas próprias questões, com os recursos que the são disponíveis. Faltando um árbitro superior, a ciência decide sobre seus problemas e respostas, sobre seus métodos para resolvê-los bem como sobre a confiabilidade relativa deles. Concebendo-se, desde o ponto de partida, como falível, a ciência nessa visão naturalista não pretende obter justificações e garantias absolutas. As justificações e garantias, ela as obtém a partir do respeito ao seu método hipotético-dedutivo, método de hipótese e teste de suas predições. Método este que está, ele também, sujeito a alterações, melhorias, correções: ou seja, um método que se revelou, até aqui, o melhor método de que dispomos, mas que não oferece nenhum tipo de garantia absoluta.

\section{V}

Ora, acontece que uma parte importante da investigação científica diz respeito ao que existe, ao que é real. A ciência oferece uma resposta a tais questões, semprevia conceitos feitos pelo homem, e não pode oferecer melhor (nem precisamos pedir mais). Não podendo escapar para um esquema conceitual exterior, privilegiado, infalível, a ciência pensa a questão da ve rdade imanentemente. Desde então, perde sentido ou legitimidade toda busca que persiste em tentar definir como é ou seria a realidade em termos absolutos, uma realidade que seria concebida transcendentalmente ao pensar em modos de existência fora dos parâmetros ditados pela própria ciência.

O ponto é, então, que, não reconhecendo o naturalismo nenhuma verdade mais elevada do que aquela que a ciência oferece ou procura, nós 


\section{2}

não podemos senão falar sempre de dentro de nosso sistema de mundo corrente quando estamos atribuindo verdade, não há outro modo de falar. É certo que "nosso sistema muda, sim. Quando ele o faz, nós não dizemos que a verdade mudou com ele; nós dizemos que nós havíamos erroneamente suposto que algo era verdadeiro e aprendemos depois que não. Falibilismo é a palavra-chave, não relativismo. Falibilismo e naturalismo" (QUINE, 1981, pp. 33-34, nossos itálicos).

Ocorre que, pelas mesmas razões por que o naturalismo recusa uma filosofia primeira, deve também recusar a idéia de um parâmetro último para além da teoria que ora entretemos. Mas, sendo esse o caso, vemos que assumir uma postura naturalista implica recusar parte crucial do próprio cenário em que a argumentação realista científica tem lugar. O cenário em questão é o apelo para uma noção transcendente de ve rdade (e realidade) com que se compromete o realismo científico. Quine e o naturalismo, ao contrário, entendem que a "verdade é imanente, e não há mais elevada". E o mesmo vale para toda atribuição de realidade, que deve ser feita de dentro de uma teoria do mundo: "é incoerente de outro modo".

Estabelecer essa distinção é crucial. De fato, essa distinção mostra imediatamente por que a "conciliação" propiciada pelo naturalismo (entre relatividade ontológica e realismo) não está disponível para o realismo científico. Isso significa, em primeiro lugar, que aquilo que conta como condição necessária e suficiente para um realista se dizer "científico" não é o que conta como condição necessária e suficiente para um realista se dizer "naturalista". De outro lado, isso significa que aquilo que conta como crítica e ameaça à postura realista científica não necessariamente se constitui como crítica ou ameaça à postura realista naturalista.

Que Quine não pode ser um realista científico, esse é um ponto praticamente incontroverso. Que Quine não possa abraçar nenhuma concepção de realismo, isso é que tentamos mostrar não ser o caso. A possibilidade de reconciliação entre realismo e relatividade ontológica é o naturalismo, com sua concepção imanentista de verdade e realidade. $\mathrm{O}$ que vemos é que essa "redefinição do cenário" não apenas permite a Quine ser realista, mas mesmo o obriga, num certo sentido, a sê-lo.

O ponto importante a ressaltar aqui é que, apesar de criticar severamente a posição realista científica, as doutrinas anti-realistas parecem aceitar, ainda que tacitamente, as "regras do jogo", elas parecem desen- 
volver todo seu enredo no interior desse “cenário”. Realmente, o que parece ser tacitamente assumido também pelo anti-realismo é a existência possível de uma teoria verdadeira que pode servir de parâmetro último, capaz de fornecer as respostas cabais para todas as nossas possíveis questões. Vamos explorar um pouco essa idéia.

O realista científico diz que as teorias científicas atuais, dado seu sucesso preditivo, devem ser consideradas boas aproximações em relação a essa teoria verdadeira última. Nesse caso, as entidades postuladas por tais teorias são assumidas como existentes e aproximadamente tais como as descrevem as teorias científicas atuais. A posse efetiva de tal teoria final decidiria a questão, isto é, diria se realmente as nossas seqüências de teorias constituíram aproximações sucessivas a essa descrição verdadeira última. Definiria, por exemplo, se elétrons existem e quão próxima da verdade a descrição do elétron fornecida pela teoria T chegou. $A$ aceitabilidade da proposta do realismo científico depende assim, em primeiro lugar, da noção de uma teoria verdadeira última e, em segundo lugar, do fato de as teorias científicas atuais se aproximarem dessa verdade. A existência de tal teoria ultimamente verdadeira, por sua vez, implica a aceitação de uma noção transcendente de verdade.

O anti-realista, por outro lado, diz não saber se tais entidades existem realmente ou não. Quarks podem existir realmente ou não, mas dadas as nossas condições presentes de conhecimento (que incluem considerações sobre subdeterminação, por exemplo), não temos como decidir a respeito. Acreditamos que a teoria dá conta dos fenômenos, mas o máximo que podemos fazer é crer em sua ve rdade quanto aos observáveis (lembremos de Van Fraassen: o cientista só deve crer na adequação empírica da teoria, isto é, que ela é verdadeira quanto aos observáveis). Quanto aos inobserváveis, devemos ser agnósticos.

Acontece que, recusada a noção de uma ve rdade transcendente, não fica bem claro o que significa ser, em princípio, agnóstico sobre a existência dos objetos inobserváveis. É claro que uma posição naturalista não impede o cientista de declarar-se agnóstico sobre a existência de determinadas entidades. Entretanto, não se trata de um agnosticismo "em princípio". Antes, quando um cientista declara ser agnóstico ou ter dúvidas sobre um determinado aspecto da teoria científica - digamos, a postulação de certa entidade -, suas dúvidas devem ser entendidas como 


\section{4}

tensões internas à própria teoria científica, como uma espécie de "falha", se se quiser, por parte desse aspecto da teoria ou dessa entidade, em satisfazer os próprios critérios do método científico.

A ciência presente pode, assim, ter dúvidas, questões não muito bem definidas e algumas respostas em aberto; entretanto, se somos naturalistas, nenhuma dessas dúvidas tem suas possíveis respostas fora de uma ciência humana, atual. Na verdade, o ponto é estabelecido por Quine de modo ainda mais impactante: se não há verdade a ser encontrada fora da ciência, se a ciência presente é o árbitro mais elevado para decidir questões de verdade e realidade, então a conclusão que se impõe é que, dentro do naturalismo, não há questões que sejam ao mesmo tempo significativas e em princípio irrespondíveis ${ }^{1}$.

Realmente, tratando ve rdade e realidade imanentemente, recusando pontos de vista privilegiados exteri o res ou futuros, é a ciência atual que tem a palavra final sobre o que considerar como existente ou não. Ora, se a ciência atual tem a palavra final, não há como sustentar que incertezas sobre matéria de existência sejam em princípio insolúveis dentro da própria ciência. Deste modo, um agnosticismo tout court sobre inobserváveis, não importa quão amplas e boas sejam as evidências que venham a estar disponíveis para o cientista, não parece aqui ter lugar. Se a ciência for tida como o árbitro final e mais elevado, uma atitude realista quanto às entidades requeridas para a teoria ser verdadeira - no caso de satisfeitos os critérios metodológicos do método científico em questão - parece decorrer naturalmente.

Essa algo longa digressão sobre agnosticismo e anti-realismo tem o intuito de realizar um trabalho de descolagem. Com efeito, trata-se de descolar a proposta quineana não apenas do realismo científico, mas das tradicionais propostas anti-realistas. A descolagem mais importante, então, é a desse "óbvio anti-realismo científico quineano" das tradicionais propostas anti-realistas em filosofia da ciência. Tal descolagem é crucial para perceber, desde já, que esse anti-realismo científico quineano não se alinha junto às demais propostas anti-realistas científicas, para perceber que Quine é não apenas um anti-realista científico, mas também - se nos for permitida a expressão - um anti-anti-realista científico. Recusado o cenário anterior, isto é, recusados ambos os lados da contenda, resta a Quine assumir a posição que lhe cabe, a de realista, sim, mas um realista naturalista. 
Acreditamos que os argumentos ora aventados são inteiramente suficientes para defender uma coerente postura realista para Quine. Gostaria aqui, entretanto, de explorar adicionalmente um aspecto da teoria quineana que talvez venha sendo negligenciado: o fato de que a visão de Quine a respeito de subdeterminação mudou ao longo de sua obra e que isso pode ter conseqüências importantes para o modo como enxergamos tanto a tese da relatividade ontológica quanto o realismo quineano.

Com efeito, pela tese da relatividade ontológica, e nuncia-se que, do ponto de vista estrito da evidência, "é indiferente para o sucesso da teoria em suas predições possuir esta ou aquela ontologia" (QUINE, 1990, p. 31). A relatividade ontológica vai, assim, apontar para o fato de que a relação da teoria com a evidência depende fundamentalmente da estrutura lógica da mesma e que, portanto, se pode mudar a ontologia da teoria sem dano para seu suporte evidencial. Que duas teorias podem, portanto, ser empiricamente equivalentes e, ainda assim, ter ontologias distintas. Empiricamente equivalentes, isto é, elas têm as mesmas conseqüências empíricas, contam com o mesmo suporte empírico.

Essa tese pode ser demonstrada, por exemplo, a través do que Quine chamou de proxy functions. Proxy function é uma espécie de mapeamento de um universo dentro do outro, mapeamento que nos mostra como um domínio de objetos pode ser eliminado - por meio de uma reinterpretação - em favor de algum outro universo (ou domínio de objetos) (QUINE, 1969, p. 55; QUINE, 1994, pp. 17-19).

Um exemplo que pode ser dado é o seguinte. Suponhamos uma proxy que reinterp rete cada objeto de uma formulação de modo a designar, em seu lugar, seu complemento cósmico. Deste modo, "Zeca" não mais designaria o cachorro, mas o cosmos inteiro menos o cachorro; o mesmo valendo para os demais objetos. "Reinterp retando o resto de nossos termos para corpos de modo correspondente, nós terminamos com uma ontologia intercambiável com a nossa familiar" 2 . Naturalmente,"como [ocorre com] todas [as demais], elas são empiricamente indistingüíveis. Corpos continuam, sob cada reinterpretação, a ser distintos de seus complementos cósmicos (...); eles são distinguidos 


\section{6}

num modo relativístico, por seus papéis relativos um ao outro e ao resto da ontologia" (QUINE, 1990, pp. 33-4).

Tratar-se-ia, portanto, de um caso clássico de subdeterminação, em que as respectivas ontologias seriam subdeterminadas pela evidência empírica disponível. Sendo empiricamente equivalentes, ambas as teorias, embora com ontologias diferentes, teriam o mesmo suporte evidencial. Exemplo similar de subdeterminação pode ser obtido através do famoso experimento quineano da tradução radical. O exemplo de 'gavagai' vem, naturalmente, aqui à mente. Tendo observado os nativos dizerem 'gavagai' sempre que na presença de um coelho, o lingüista propõe "coelho" como sua tradução privilegiada. Mas o que impediria o lingüista de escolher "coelhidade" ou "“partes indestacáveis de coelho"? - pergunta Quine. Sem entrar aqui em maiores detalhes, cabe salientar que tais traduções, embora incompatíveis entre si, são compatíveis com todos os comportamentos verbais dos falantes, e, portanto, não haveria como justificar, de um modo puramente empírico, a preferência de uma tradução em relação à outra (QUINE, 1969, pp. 31-35).

Queremos chamar a atenção aqui, porém, para as alterações que a doutrina da subdeterminação sofreu e que podem dar novas cores à problemática da relatividade ontológica e suas implicações para a discussão sobre realismo ou anti-realismo. De fato, essa é uma questão que parece crucial. Assim, ao examinar a questão concernente a duas teorias empiricamente equivalentes, Quine se pergunta: se elas são empiricamente equivalentes, em que sentido são duas teorias (em oposição, por exemplo, a duas formulações da mesma teoria)?

Em busca dessa resposta, ele define: duas formulações expressam a mesma teoria se elas são empiricamente equivalentes e há uma reconstrução de predicados ${ }^{3}$, reinterpretação de termos ou inter-tradução que transforma uma teoria num equivalente 4 lógico da outra (QUINE, 1975a, p. 320; QUINE, 1994, p. 29). Entendamos o que está em jogo através de alguns casos.

(A). Suponha duas formulações de teoria, idênticas uma à outra, exceto pelo fato de que alteramos dois de seus termos que são puramente teóricos, isto é, que não aparecem em nenhuma sentença de observação, por exemplo, molécula e elétron. Assim, o que uma formulação chama de molécula, a outra chama de elétron, e vice-versa 
(QUINE, 1975a, p. 319; QUINE, 1975b, p. 80; QUINE, 1987, p. 517; QUINE, 1994, p. 28).

Claramente as duas formulações são empiricamente equivalentes, pois implicam os mesmos categóricos observacionais. De fato, os categóricos observacionais permanecem idênticos, já que eles não contêm aqueles termos. Entretanto, as duas formulações da teoria estão em contradição, são logicamente incompatíveis, pois o que uma diz sobre moléculas, a outra nega e atri bui aquelas propriedades a elétrons (QUINE, 1975a, p. 319; QUINE 1975b, p. 80; QUINE, 1994, pp. 28-9).

Temos, desde então, duas opções.

Ou entendemos tratar-se de duas teorias alternativas ou rivais explicando as observações, as quais discordam a respeito das propriedades de elétrons e moléculas, ou temos uma teoria e uma diferença terminológica (QUINE, 1987, p. 517).

Quine entende que optar pela primeira alternativa seria como que trivializar a diferença entre teorias, pois mesmo o "homem da rua" protestaria dizendo que se trata da mesma teoria, já que bastaria trocar de volta os dois termos para o conflito ser resolvido. Em termos mais técnicos, o conflito poderia ser trivialmente "resolvido tratando uma formulação como não inteiramente portuguesa, e traduzir suas respectivas palavras 'molécula' e 'elétron' pelas portuguesas 'elétron' e 'molécula", (QUINE 1975a, pp. 319-320; QUINE, 1987, p. 517).

Em outras palavras,

"relativamente ao manual de tradução homofônico - a transformação de identidade -, os dois textos de fisica estão em contradição lógica.

Relativamente a outro e melhor manual de tradução, o qual é homofônico exceto para traduzir molécula por elétron e vice-versa, os dois textos concordam inteiramente. O segundo manual de tradução é melhor no fato de que ele maximiza a concordância" (QUINE, 198 7, p. 517) (nossos grifos) ${ }^{5}$.

Deste modo, com a reinterpretação dos termos em uma formulação, as duas formulações são tornadas idênticas e, deste modo, esse exemplo não vale como um bom caso de rivalidade entre teorias. Quine, por isso, nega que haja qualquer diferença real: as duas formulações devem ser consideradas, antes, como formulações da mesma teoria (QUINE, 1975a, p. 319; QUINE, 1987, p. 517). 


\section{8}

(B). Um outro "exemplo familiar é a geometria riemanniana e a euclidiana enquanto aplicada à superfície de uma esfera. A geometria riemanniana diz que linhas retas sempre se encontram. A geometria euclidiana diz que algumas se encontram, e outras não, e em particular que não há nenhuma numa esfera". Aqui também, o conflito pode ser resolvido por meio de uma reinterpretação, nesse caso "reinterpretando 'linha reta' no glossário riemanniano como ‘círculo máximo”” (QUINE, 1990, p. 96).

(C). Ora, o que devemos observar nesse momento é que também a permutação dos objetos realizada pelas proxy functions gera, similarmente, um conflito que pode ser facilmente resolvido. De fato, o que faz uma proxy function senão realizar uma reinterpretação dos predicados ( $\mathrm{da}$ formulação) da teoria, fazendo correlações um-a-um entre os antigos e os novos objetos e preservando, deste modo, todas as conexões lógicas?

Mas, se assim é, no caso de duas formulações de teoria, uma qualquer e sua proxy, elas tampouco valerão como um bom caso de rivalidade no momento em que tal conflito pode ser resolvido também por meio de reinterp retação de termos ou predicados, nesse caso fazendo o mapeamento contrário. Desta forma, também aqui, as duas formulações são tornadas idênticas [reconciliadas] via reinterpretação dos termos em uma das duas formulações. Mas, nesse caso (como no caso visto de Zeca e seu complemento cósmico), diante de tais formulações conflitantes, nós também poderíamos declarar tal conflito como meramente terminológico.

De fato, as duas formulações estão em conflito relativamente a um manual de tradução homofônico. Entretanto, nós poderíamos tratar a segunda formulação como não sendo (inteiramente) portuguesa e traduzir "complemento cósmico de Zeca" por "Zeca” e vice-versa, o mesmo procedimento sendo aplicado aos demais objetos. Com isso, relativamente agora a esse outro e melhor manual de tradução, os dois textos passam a concordar inteiramente. Novamente, esse manual de tradução é melhor pelo fato de que ele maximiza a concordância, isto é, ele reconcilia uma formulação com a outra sem perturbar, naturalmente, os seus respectivos conteúdos empíricos.

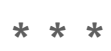

doispontos, Curitiba, São Carlos, vol. 4, n. 2, p.133-158, outubro, 2007 
Ou seja, o que Quine está dizendo é que formulações de teoria empiricamente equivalentes para as quais encontramos um modo de intertradução não contam como exemplos válidos de rivalidade ou de subdeterminação. Os únicos casos agora que contam como exemplos legítimos de subdeterminação, o conflito verdadeiramente significativo será, então, aquele entre "formulações de teoria que se mostrem empiricamente equivalentes, logicamente incompatíveis e, ponto-chave, que não possam ser reconciliadas via qualquer tipo de reconstruãa de predicados ou tradução. É esse o conflito que requer reconhecimento, é esse conflito que explicita o que está realmente em jogo na doutrina da subdeterminação" (QUINE, 1975a, p. 322) ${ }^{6}$.

Ora, ocorre que o conflito posto pela relatividade ontológica não entra nesse caso específico. Sim, pois vimos que, se de um lado, as proxy functions nos ensinam a gerar teorias com ontologias distintas preservando sua estrutura lógica e, portanto, seu conteúdo empírico; vimos, de outro lado, que o caso das proxy functions podem ser relidos como casos de indeterminação da tradução.

Em outras palavras, temos que essas duas teorias contavam aparentemente como duas teorias, mas, a partir de um manual de tradução adequado, podem agora ser pensadas como duas formulações da mesma teoria e, portanto, como um conflito não significativo ou desinteressante.

Ora, parece que aqui se podem tirar pelo menos duas conseqüências a nosso ver importantíssimas.

- A primeira é que a tese da relatividade ontológica talvez não possa ou não deva mais ser utilizada como argumento para dizer de Quine que é anti-realista. Pelo menos não quando vemos como enunciar regras de tradução que reconciliariam as duas teorias empiricamente equivalentes. E isso simplesmente porque não se pode mais dizer que se tratava de duas teorias.

- A outra conseqüência é perceber que há várias maneiras, vários discursos igualmente defensáveis capazes de descrever o mundo, o universo. Mas que, apesar disso, precisamos recorrer a um deles, e que é nesse discurso, em suas palavras, que vamos descrever a realidade.

Ora, mas concordar com isso não equivaleria a dizer que, para Quine, o discurso, as palavras e conceitos que utilizamos teriam um papel meramente instrumental e que, portanto, as acusações de anti-realismo entrariam pela porta do fundo? 
Aqui devemos lembrar do debate anterior. Se tomarmos como base o cenário em que se movem realistas e anti-realistas científicos, por exemplo, a resposta seria certamente sim. Entretanto, não podemos esquecer que, para Quine, não há filosofia primeira, não há verdade transcendental, como não há, tampouco, a possibilidade de uma realidade não conceitualizada.

Deste modo, se é verdade que a decisão quanto a que discurso utilizar - entre dois discursos empiricamente equivalentes e inter-traduzíveis, naturalmente - traz algo de arbitrário (no sentido de empiricamente indeterminado), ainda assim temos de escolher um discurso e será nos seus termos, nos termos dessa teoria, imanentemente portanto, que a realidade será descrita. Não pode ser diferente e não precisamos pedir melhor.

A conseqüência que talvez tenhamos de tirar é não que Quine não possa ser um realista - ele o é - mas que, para Quine, o discurso, as palavras e conceitos utilizados não têm nenhum vínculo essencial com a natureza descrita. Usamos o discurso para falar da realidade, sim, mas o mesmo não é, em nenhum sentido - para tomar de empréstimo uma expressão de Rorty - um "espelho da natureza".

\section{VII}

Ora, o que podemos acrescentar e perceber é que essa postura filosófica quineana pode ser bem aproximada de uma postura pirrônica ou neopirrônica.

Comecemos ressaltando alguns pontos centrais da postura pirrônica.

Ao investigar com rigor e espírito crítico as várias doutrinas que pretendem ter atingido o conhecimento absoluto do mundo, o cético pirrônico chega à conclusão de que não há ou não tem havido por que dar o seu assentimento antes a uma determinada doutrina do que a uma outra, que muitas vezes se opõe à primeira de modo drástico. Uma vez, porém, tendo suspendido o juízo sobre as doutrinas e teorias que tentam dizer como é o mundo em si mesmo, o cético pirrônico não pode "deixar de reconhecer que temos uma experiência de mundo que epokhé nenhuma vem afetar" (PORCHAT, 2001, p. 14). Essa experiência de mundo, fenomênica, o pirrônico aceita, sem problemas, mas ele a aceita 
precisamente enquanto fenômeno, enquanto aparecer, enquanto ela se dá, de modo irrecusável, à sua experiência.

O ceticismo pirrônico substitui coerentemente, assim, o pretenso saber teórico e dogmático pelo saber da experiência. Todo o saber de que se vale o cético é agora saber do fenômeno, isto é, saber empírico. "Mas se trata sem dúvida de um empirismo sem dogmas". Por quê? Porque para o ceticismo, privilegiar o fenômeno não equivale a transformá-lo em critério de verdade absoluta. É assim que o cético pirrônico pode, mesmo "tendo suspendido o juízo sobre toda a epistéme, fazer a apologia das tékhnai, que podem ser utilizadas e defendidas pelos céticos porque elas precisamente lidam apenas e diretamente "com os fenômenos, que elas observam e sistematizam" (PORCHAT, 2001, pp. 17-8).

Ora, sendo assim, e ainda seguindo Porchat, estamos autorizados a dizer que um pirrônico moderno bem poderia ver as teorias científicas modernas como uma espécie de sofisticação das antigas tékhnai, e o método científico-empírico da ciência moderna como uma sofisticação do método empírico das tékhnai que o pirronismo, vimos, explicitamente adota.

Ora, parece-nos que essa postura pirrônica não difere tanto da postura naturalista quineana.

Realmente, assim como Quine, o pirronismo:

- recusa a noção de uma filosofia primeira, capaz de oferecer um ponto de vista privilegiado e exterior, capaz de fundar, de fora, o conhecimento do mundo e das coisas;

- recusa a existência de uma descrição definitiva, última e acabada do mundo;

- recusa o fato de que a ciência venha a se tornar, mesmo no limite, um conhecimento das coisas em si mesmas;

Entretanto, ao fazê-lo, o pirrônico não deixa de reconhecer a necessidade de se valer de um discurso para descrever o mundo, para descrever essa experiência de mundo que nós temos. Essa descrição, clara e forçosamente, se fará no interior do quadro fenomênico. Isto é, o pirrônico falará de verdade e realidade "no interior de um quadro mundano reconhecidamente moldado com a contribuição de seu aparato conceitual e lingüístico” (PORCHAT, 1995, p. 44). 
Ora, o que vemos aqui é que também o cético - assim como o naturalista quineano - falará de verdade e realidade apenas imanentemente. Também o cético não dará às palavras um peso metafísico, não lhes atri buirá o papel ou a capacidade de "espelharem" a realidade em si mesma.

Ou seja, cabe ver que tanto em Quine quanto no neopirronismo, as palavras, a linguagem, são nossos instrumentos privilegiados a partir dos quais podemos relatar nossa experiência de mundo. Mas que, uma vez rejeitadas as pretensões de uma descrição absoluta da realidade, uma vez rejeitado esse papel "essencialista" da linguagem, nem por isso a linguagem precisa ser reduzida a um papel meramente instrumentalista.

Em outras palavras, o que talvez haja em comum tanto na postura quineana quanto numa postura neopirrônica é que, desde o momento em que abandonamos toda pretensão absoluta de conhecimento, de espelhar a natureza através de nossos discursos ou teorias, não nos resta outra possibilidade senão dar o crédito e o mérito às palavras de nossas melhores teorias de dizerem do mundo o que ele é, de dizer como ele é.

Essas palavras, esses conceitos de nossas melhores teorias, descrevem, sim, o mundo e seus objetos; através dessas palavras, dessas noções - eleitas por razões reconhecíveis (por exemplo, por sua capacidade de sistematizar a nossa experiência de mundo) - descrevemos a realidade e dizemos o que existe. Não a realidade em si mesma, não a descrição absoluta e plena da realidade - já que abdicamos das pretensões absolutas de justificação disso que chamamos nosso conhecimento - mas ainda assim a realidade. Não um realismo científico (ou sua contra-parte, o anti-realismo científico). Não um realismo metafísico, mas, ainda assim, um realismo. Seja ele naturalista, seja ele neopirrônico.

\section{VIII}

Talvez uma última observação ainda deva ser feita.

Freqüentemente se ouve de críticos e debatedores do tema que tal definição de realismo, quineano por exemplo, não é possível ou mesmo coerente. Que essa alegada postura realista nada tem, afinal, de realista. 
E certamente eles têm razão. Ocorre que eles têm razão enquanto, e apenas enquanto, eles se apegam ao cenário anterior de debate.

Ocorre que o cenário de discussão epistemológica mudou.

Tomemos como analogia o debate histórico a respeito da noção de conhecimento. Se entendermos a noção de conhecimento como epistéme ou como conhecimento absolutamente certo, eterno, indubitável, poderíamos bem ser levados a admitir que o conhecimento é impossível. Acontece que, assumindo isso, ficaríamos como que "órfãos", sem poder recorrer a uma noção, a um conceito de extrema importância filosófica.

Quis o bom senso que os filósofos tenham optado não por abandonar a noção de conhecimento, mas por ressignificá-la, redefini-la. Não foi um processo simples ou rápido, mas a noção de conhecimento agora comporta falibilidade, graus de confiabilidade, probabilidade, incerteza e hoje nos parece plenamente natural assim pensarmos.

Ora, o problema, a nosso ver, é que a noção de realismo precisa, mutatis mutandis, acompanhar o mesmo processo de ressignificação. $\mathrm{O}$ problema todo parece estar em que precisamente a discussão sobre realismo versus anti-realismo protagoniza o último ou um dos últimos baluartes da "vontade de absoluto" em matérias epistemológicas.

Sim, p o rque se é ve rdade que as reflexões epistemológicas contemporâneas nos fizeram aceitar que nossas melhores teorias científicas são falíveis, a doutrina do realismo científico como que reintroduz - pela porta dos fundos - a noção de conhecimento absoluto ao postular tácita ou explicitamente uma teoria ultimamente verdadeira, verdade da qual nos aproximaríamos com nossas teorias científicas atuais, crescentemente poderosas. Ora, é essa reintrodução do absoluto - ilegítima a nosso ver porque apela para uma noção transcendente de verdade - que precisamente norteia o debate entre realismo e anti-realismo científicos.

Certamente não devemos aqui - a partir da crítica feita em relação à aceitação de uma noção transcendente de verdade - conferir ao realismo científico o mesmo estatuto que aquele dado ao realismo transcendental ou metafisico. De fato, o realismo científico se distancia - e muito - das antigas propostas realistas metafísicas e suas pretensões de conhecimento da "coisa-em-si-mesma". Com efeito, para o realismo científico, nenhuma entidade é jamais admitida como existente sem o respaldo do sucesso empírico, preditivo da teoria científica em questão. Nesse sentido, o 


\section{4}

realista científico pretende oferecer não descrições das coisas-em-simesmas (como faz o realista metafísico), mas antes das "coisas-para-asteorias-científicas-bem-sucedidas"7. Neste contexto, lembrar Kant pode ser oportuno. Isso porque "Kant foi o primeiro filósofo a ter mostrado (...) que a rejeição do realismo metafísico (que ele chamou de transcendental) não implica necessariamente a recusa de toda postura que se possa legitimamente chamar de realista" (PORCHAT, 1995, p. 19). E, de fato, o filósofo mostrou, na sua filosofia, que o idealismo transcendental não é incompatível com um realismo empírico ${ }^{8}$.

Entretanto, cabe ressaltar que, distante embora do realismo metafísico, o realismo científico, ao se comprometer com uma teoria ultimamente verdadeira, acaba por ancorar suas teses sobre um modo transcendente de justificação e reintroduz, assim, um elemento indisfarçavelmente "metafísico" nas suas concepções.

Ora, ocorre que, se podemos dizer que Kant nos mostrou que não é preciso ser metafísico para ser realista, Quine nos mostrou que não é preciso recorrer a nenhum modo transcendente de justificação para defender uma concepção realista para a ciência. De fato, ao rejeitar ambos, realismo metafísico $e$ realismo científico, o empirismo quineano nem por isso é menos realista. Com efeito, Quine consegue prescindir da idéia de uma teoria ultimamente ve rdadeira como parâmetro de justificação para as verdades propostas pelas teorias científicas e, em seu lugar, oferecer uma doutrina da realidade e da verdade imanente ao discurso teórico que organiza o domínio empírico. Quine consegue isso, vimos, via naturalismo. Via naturalismo, Quine encontra a via para uma concepção renovada - e não dogmática - de realismo em ciência.

Mas se assim é, quer nos parecer que, no momento em que realmente conseguirmos abdicar dessa idéia de uma teoria ultimamente verdadeira e assumirmos toda tentativa de conhecimento como um empreendimento eminentemente humano e falível, sem pretensões absolutas ou transcendentes de justificação, acabaremos fatalmente por perceber que o debate tradicional entre realismo e anti-realismo científicos perdeu seu único sustentáculo e não tem mais lugar ou mesmo pertinência.

Ora, no momento em que isso acontecer, teremos de decidir se queremos ficar "órfãos" dessa noção, desse conceito filosófico de inequívoca importância e utilidade ou se, como tantas outras vezes na história da 
filosofia, optaremos por ressignificar, redefinir o conceito de realismo de um modo condizente e consistente com a evolução do resto do debate epistemológico9 .

E quer nos parecer que essa ressignificação, essa redefinição já pode ser vislumbrada, quer nos parecer que tanto o realismo naturalista quineano quanto o que poderíamos pensar como um realismo neopirrônico podem fazer plena justiça ao estado atual das reflexões filosóficas. Resta apenas esperar que a resistência, que esse antigo ranço ceda, que o apego ao absoluto perca sua força remanescente para que essas posturas filosóficas possam ganhar toda a legitimidade que merecem.

1 "A questão era se há questões - questões significativas a que o homem poderia em princípio nunca responder. Nesta filosofia, a resposta a esta questão é não" (QUINE, 1976, p. 67).

2 Observe-se que, no caso das proxy functions, não há pro blema de os termos eventualmente ocorrerem também nos categóricos observacionais, uma vez que a reinterp retação feita não altera em nada a sua estrutura lógica e, conseqüentemente, a relação da formulação da teoria com o suporte evidencial.

3 Observe-se que essa reconstrução ou reinterpretação de predicados não precisa obedecer a limites estreitos. Com efeito, Quine nos diz que "não deveríamos limitar a permutação a uma troca de dois predicados; nós deveríamos permitir permutação de muitos. Finalmente, seria arbitrário requerer dessa transformação que se limitasse a transformar predicados sempre em predicados simples de uma palavra. A noção intuitiva, afinal, era uma reconstrução de predicados; e o modo geral de reconstruir um predicado de $\mathrm{n}$ lugares é provendo uma sentença aberta em $\mathrm{n}$ variáveis, não importando se efetivamente existe uma palavra em nossa linguagem com a mesma extensão que aquela sentença aberta". Na seqüência, Quine precisa sua definição de reconstrução de predicados. "Por uma reconstrução de predicados de nossa linguagem, correspondentemente, quero dizer qualquer mapeamento de nosso léxico de predicados em nossas sentenças abertas (predicados de n-lugares para sentenças de nvariáveis). Assim, o predicado "mais pesado que" pode ser mapeado para a sentença aberta " $\mathrm{x}$ é mais pesado que y", um mapeamento de identidade não mudando nada, enquanto os predicados 'molécula' e 'elétron' podem ser mapeados para as respectivas sentenças abertas 'x é um elétron' e 'x é uma molécula', produzindo nosso exemplo” (QUINE, 1975a, p. 320).

${ }^{4}$ Note-se que a reconciliação via reconstrução de predicados não precisa exigir a identidade de formulações. Realmente, "desde que formulações logicamente equivalentes deveriam em qualquer caso contar como formulações da mesma teoria (cf. supra), nós não deveríamos exigir que uma troca de termos torne as formulações idênticas; nós deveríamos exigir apenas que ela as torne logicamente equivalentes". Diremos, assim, que as teorias são as classes de equivalência daquela relação de equivalência. São classes, portanto, de formulações de teoria. (QUINE, 1975a, pp. 320-321).

doispontos, Curitiba, São Carlos, vol. 4, n. 2, p.133-158, outubro, 2007 


\section{6}

${ }^{5}$ Cf. também Theories and Things (QUINE, 1994, p. 29): “A resposta natural a esse exemplo trivial é que as duas formulações são realmente formulações da mesma teoria em palavras ligeiramente diferentes, e que uma pode ser traduzida na outra trocando as duas palavras novamente" (nosso itálico).

${ }^{6}$ Em Pursuit of Truth (QUINE, 1990), ao contrário, a questão da incompatibilidade lógica é superada, e a subdeterminação passa a dizer respeito apenas a (formulações de) teorias empiricamente equivalentes, logicamente compatíveis, mas conflitantes agora no sentido de a teoria alternativa à nossa conter termos teóricos não redutíveis aos nossos. Para efeitos da argumentação aqui empreendida, no entanto, essa alteração não traz efeitos significativos.

${ }^{7}$ Gostaríamos de registrar aqui nossos agradecimentos aos comentários e sugestões recebidos no parecer a esse trabalho.

8 Para uma argumentação mais detalhada sobre o realismo empírico kantiano, ver PORCHAT, 1995, pp. 19 e segs.

${ }^{9}$ Um adendo pode ser feito aqui. Observe-se que, ao defender o abandono dos "absolutos" em filosofia, naturalmente entendemos que isso representa um "progresso" em relação ao modo de pensar anterior. No entanto, concebemos esse "progresso" de modo "trivial". Trivial no sentido de que nós sempre e naturalmente defendemos aquelas concepções que acreditamos serem as melhores, segundo nossos parâmetros presentes. Em nenhum momento, porém, tem essa idéia de "progresso" qualquer relação com uma "direção" preestabelecida, nem tampouco implica isso que as doutrinas filosóficas futuras serão, necessariamente, melhores do que as passadas. Naturalmente, nunca queremos mudar para pior. Mas nunca estamos livres de dizer, retroativamente, que tal caminho tomado foi ruim ou equivocado. Em cada momento pontual, porém, dentro de nossa visão, de nosso sistema global de mundo, temos valores e parâmetros a partir dos quais julgar os méritos e deméritos das teorias ou concepções concorrentes. Deste modo, coerente com a postura naturalista (e/ou pirrônica), no presente, de acordo com os parâmetros atuais, imanentes a essa visão, entendemos que a filosofia tem a ganhar, e muito, com o abandono dos absolutos.

Uma proveitosa analogia pode ainda ser feita.

O realismo científico é aquela concepção que entende que as teorias científicas progridem numa determinada direção (na direção da teoria ultimamente verdadeira) e seu progresso é mensurado de acordo com isso. $\mathrm{O}$ realismo naturalista, por sua vez, não estabelece nenhuma direção prévia para onde a ciência deve caminhar. Ao contrário, ele entende que os parâmetros que permitem julgar as teorias científicas são mutáveis, assim como o próprio método científico a elas subjacente. Deste modo, o assim chamado "progresso científico" não precisa ser linear nem caminhar numa direção pré-determinada. E é por essa razão que o naturalismo não apresenta, nem precisa, uma doutrina da aproximação à verdade ou da preservação relevante de elementos da teoria anterior na posterior. Similarmente, podemos falar no abandono dos absolutos como um progresso sem com isso pretender estabelecer nenhuma direção ou rumo preestabelecido para as reflexões filosóficas, seja do passado em direção ao presente, seja do presente em relação ao futuro.

doispontos, Curitiba, São Carlos, vol. 4, n. 2, p.133-158, outubro, 2007 


\section{Referências bibliográficas}

BOYD, R. 1984. "The Current Status of Scientific Realism”. In:

LEPLIN, J (ed.) Scientific Realism. Berkeley: University of California Press, pp. 41-82.

. 1990. "Realism, Approximate Truth And Philosophical Method", in: SAVAGE, W (ed.) Scientific Theories, Minnesota Studies in the Philosophy of Science, vol. XIV, Minneapolis: University of Minnesota Press, pp. 355-391.

BULCÃO NASCIMENTO, M. 2005. O Realismo Naturalista de Quine: Crença e Conhecimento sem Dogmas. São Paulo. 208p. Tese (Teoria da Ciência). Universidade de São Paulo.

PORCHAT PEREIRA, O. 1995. "Realismo, Verdade, Ceticismo”, In: Discurso n. 25. São Paulo: Discurso Editorial, pp. 7-67. . 2001. “Ainda é preciso ser cético”, In: Discurso n. 32. São Paulo: Discurso Editorial, pp. 9-30.

QUINE, W.V. 1953. From a Logical Point of View. Cambridge, Massachusetts: Harvard University Press. 1966. The Ways of Paradox and Other Essays. New York: Random House. 1969. Ontological Relativity and Other Essays. New York :

Columbia University Press. . 1975a. "On Empirically Equivalent Systems of the World". In: Erkenntnis n. 9, pp. 313-328. . 1975b. "The Nature of Natural Knowledge". In:

GUTTENPLAN, S. (ed.) Mind and Language. Oxford: Clarendon Press, pp. $67-81$. . 1976. The Ways of Paradox and Other Essays (Revised and Enlarged Edition). Cambridge, Massachusetts and London: Harvard University Press. . 1981. “The Pragmatist's Place in Empiricism”. In: MULVANEY, 
R. J. and ZELTNER, P. M. (eds.) Pragmatism: its sources and prospects. Columbia: University of South Caroline Press, pp. 21-39. 1987. Reply to J. J. C. Smart's “Quine on space-time”. In:

SCHILPP, P.A.; HAHN, L.E. (eds.) The Philosophy of W.V. Quine. La Salle, Illinois: Open Court.

_. 1990. Pursuit of Truth, Cambridge: Harvard. . 1992. "Structure and Nature", in: The Journal of Philosophy, vol. 89, n. 1, pp. 5-9. 1994. Theories and Things. Cambridge, Massachusetts: Harvard University Press.

VAN FRAASSEN, B. 1980. The Scientific Image. Oxford: Clarendon Press. 